\title{
Research on the Evaluation System of Classroom Teaching Based on the Cultivation of Mathematics Core Quality
}

\author{
Yaoqi Hong ${ }^{1, *}$ and Qiuhua Zhou ${ }^{1}$
}

\author{
${ }^{1}$ YuZhang Normal College, Jiangxi, Nanchang 330103 \\ *Corresponding author.Email: 76771312@qq.com
}

\begin{abstract}
The new curriculum idea has made the mathematics basic education from three dimensions to core literacy. This paper takes the mathematics classroom teaching evaluation as the research topic, and studies how to use the evaluation to promote the development of students' core literacy, thus, to promote teachers' professional level. The research aims to find the problems and reasons in the process of classroom teaching through the investigation and analysis of the traditional mathematics classroom evaluation, and combines the requirements of the core quality for classroom teaching evaluation to promote the generation of students' core qualities and teachers' professional development. This paper constructs a mathematics classroom evaluation standard and index system oriented to the core literacy on the premise of students 'development and teachers' teaching behavior and students' learning state.
\end{abstract}

Keywords: Core Literacy; Mathematics Core Literacy; classroom teaching evaluation

\section{INTRODUCTION}

In March 2014, "core literacy" firstly appeared in the Ministry of Education's "opinions on comprehensively deepening curriculum reform and implementing the fundamental task of moral cultivation" (hereinafter referred to as "opinions"), and it has been placed in the dominant position of deepening curriculum reform and carrying out the fundamental task of moral education. And the "Core Literacy" has become an important basis for developing academic quality standards to revise curriculum programs and curriculum standards. Since then, as a new direction of curriculum teaching, core literacy has become a key word in education and teaching research, and the development of students 'core literacy has become a key area of curriculum reform and an important link in the reconstruction of classroom teaching outlook. Mathematics is an important subject in the academic stage of students, and the teaching reform of mathematics education based on the core literacy of the subject has become the most popular topic in the subject field. Classroom teaching evaluation. As an important part of the whole process of teaching evaluation, classroom evaluation is an important way and an effective method for teachers to get feedback from student about teaching quality. Therefore, it is an important way to promote the reform of mathematics subject by changing the traditional teaching way and constructing an evaluation system of mathematics teaching that is suitable for the development of core literacy.

\section{DEFINITION OF RELEVANT CONCEPTS}

\subsection{Core Literacy}

Under the three basic principles of science, times and nationality, and with the cultivation of "all-round developing people" as the core literacy, China determines that the core accomplishment consists of three aspects: Cultural Foundation, Independent Development and social participation, and there are six qualities: comprehensive performance for the humanities, scientific spirit, learning to learn, healthy life, responsibility, practice and innovation. The construction of this framework claim that China puts forward the core quality as a comprehensive quality, that is the ultimate goal of education: "establish morality and cultivate people". The goal is putting forward the core literacy as a comprehensive requirement from ability to character to concept, and it is a comprehensive expression of students' knowledge, skills, feelings, attitudes, values and so on, and it is an indispensable common quality that every student needs to achieve a successful life, and to adapt to personal and social development. But it is rather an all-round quality than a key part of quality. Namely, the quality is a process of receiving school education, changing the basic knowledge and abilities, emotional attitudes and values to how to face a problem. This is ability that a student needs to have, and can adapt to personal life and social development of the personality quality. Its development is a lifelong process. 


\subsection{Core mathematic literacy}

Core Literacy, as a macro concept, must be reagarded as disciplinary literacy in order to come into effect. The core quality of a subject refers to the correct values, necessary character and key abilities that students develop through the study of the subject. "Key ability" belongs to intelligence factor, "essential character" mainly belongs to non-intelligence factor, and "correct value idea" belongs to value orientation. It must be based on "the development of core literacy of Chinese students" as the guidance, and based on the characteristics and tasks of the discipline in order to cultivate all-round development and social needs of the key literacy. Therefore, the core quality of mathematics subject should be the quality with the specical characteristics, which is based on the knowledge of mathematics subject, and aims to reflect the essence and thought of mathematics subject, and embodies the value of education of mathematics subject. Professor Ma points out that the core literacy is ten key words in his book. And Professor Cao points out that core literacy is a basic thought including abstract, reasoning, and modeling. Professor Shi points out that we should have mathematic skills to see the real world, use mathematic thoughts to analyze real world, and use mathematic language to express. Analyzing the domestic research literature, we can see that the connotation of mathematics core literacy has not been defined uniformly in our country. Through the reading research of a large number of literature materials, as well as combining our own teaching practice experience, we quite agree with Professor Ma Yun peng' s views, we believe that primary school mathematics core literacy can continue to be summed up in the curriculum standards of the 10 core concepts: number sense, symbol awareness, spatial awareness, geometry intuitive, data analysis concept, reasoning ability, operational ability, application awareness, the sense of innovation and the idea of model, in which the sense of numbers, the sense of symbols, the sense of space, the sense of geometry and the idea of mathematical analysis are expressed in mathematical language, reasoning ability, operation ability and model thinking are represented by thinking of mathematical method, and application consciousness and innovation consciousness are represented by positive mathematical emotion.

\subsection{Evaluation of mathematics classroom teaching}

"Classroom teaching evaluation, in short, is the evaluation of classroom teaching, mainly the evaluation of teachers' classroom teaching behavior and its effect. " The traditional classroom teaching evaluation continues Taylor's goal model, mainly based on the teaching goal, through the predetermined standard and the method, carries on the value judgment to the entire teaching process teacher and the student's behavior and the achievement goal result. Mathematics classroom teaching evaluation is the concrete application of classroom teaching evaluation in the field of mathematics education. It not only covers the general characteristics of classroom teaching evaluation, but also has the unique disciplinary characteristics of mathematics itself, the mathematics curriculum standard for compulsory education points out that the function and meaning of mathematics are various, it can be a tool to help people work and study, and it can also assist the study of other subjects It can also help people to form a meticulous approach to the problem, forming a spirit of perseverance; it can be the cornerstone of the development of large-scale technological engineering; It can also make people's logical reasoning ability, abstract thinking ability, space imagination can be developed; it is the element that can be seen everywhere in modern life, influencing people's life all the time and everywhere. This requires us to evaluate the mathematics classroom is no longer only to focus on students after learning mathematics knowledge results, but also to integrate their learning process into the evaluation system, pay attention to the emotional changes that occur as they learn math. At the same time, as a testing mechanism in mathematics classroom teaching activities, the evaluation of mathematics classroom teaching should regard "setting up moral character" as the basic educational task, and find and solve problems in the teaching process, then train the core accomplishment that the student needs to have for the whole life development. On the whole, mathematics classroom teaching evaluation provides important decision-making information for the development of curriculum, the use and development of teaching methods, and the cultivation of students' learning. Classroom teaching evaluation not only promotes the improvement of teachers 'teaching, students' learning and ultimate classroom teaching quality, but also guides the development direction of education and teaching.

\section{THE CHARACTERISTICS OF CLASSROOM TEACHING EVALUATION BASED ON THE CULTIVATION OF MATHEMATICS CORE LITERACY}

Ministry of Education issued "knowledge and skills", "process and methods" , "emotional attitudes and values" and "three-dimensional goals" were first put forward in the "outline of curriculum reform for basic education" in 2001 , in 2016, the overall framework of "developing core literacy for Chinese students" was officially released, moving from three-dimensional goals to core literacy. In fact, core literacy is another comprehensive goal that integrates knowledge, skills, emotions, etc., it embodies the inheritance and development of the three-dimensional object, and is the result of the concretization, integration, classification and internalization of the three-dimensional object. The evaluation of mathematics classroom teaching based on the cultivation of mathematics core quality must start from three aspects: Evaluation of "Double Base", evaluation of "problem solving" and "subject thinking". First, basic knowledge and basic skills are the core content, 
that is, "double-based" is the most basic level of evaluation; then "problem solving" is the second core content, that is to say, the second evaluation level is the basic method and ability acquired in the process of solving problems, and the third evaluation level is the core content of "discipline thinking" , this level of evaluation needs to establish a systematic and advanced evaluation system, pay more attention to the subject thinking, thinking mode, to overcome the tendency of emphasizing teaching over educating people, and to carry out the basic task of establishing morality and cultivating people. Meanwhile, through the activity experience, cognition and internalization of the process of basic knowledge construction in core literacy, the relatively stable thinking problem and the thinking method and value of solving the problem are evaluated respectively.

\section{THE DISADVANTAGES OF TRADITIONAL MATHEMATICS TEACHING EVALUATION}

Core Literacy is the guide direction of basic educaton and teaching in our country. In order to implement the core literacy into mathematics education and teaching better, the paper summarized some disadvantages from the perspective of how to teach for teachers and how to learn for studnets.

\subsection{The content of teaching evaluation lacks comprehensiveness}

Although the new curriculum standards suggest that teaching evaluation should be based on three-dimensional objectives to evaluate teaching activities in an all-round way, in the actual operation, most of the mathematics teachers evaluate the teaching from the dimension of knowledge and skills, and their evaluation of academic subject knowledge and problem-solving skills is far beyond the evaluation of students' knowledge inquiry and emotionbuilding, and even some teachers turn a blind eye to students 'inquiry process and emotional experience. In addition, Chinese traditional evaluation methods more use summative evaluation so that the content of evaluation has been completed before the class, and all use a unified standard. Each student is an independent individual, so the content of teaching evaluation can not be the same. In order to achieve a unified goal, teachers should put forward different evaluation content and should be suitable for each student, from the unified to the difference.

\subsection{The main body of teaching evaluation lacks integration}

The subject of mathematics classroom teaching evaluation has always been the focus of people's attention. With the deepening of teaching evaluation reform, the traditional form of evaluation subject with teachers as the main body and the new form of multi-evaluation subject such as student self-evaluation and group mutual evaluation came into being, mutual evaluation is a formality because of the influence of individual subjective factors, and the fusion of multi-subjects has become a problem that we are anxious to solve in teaching evaluation.

\subsection{The criteria for teaching evaluation lack emotionality}

What plays a directional and guiding role to classroom teaching evaluation is that the teaching evaluation standard, which is the value and the standard of the whole classroom teaching evaluation activity. However, the current evaluation criteria for classroom teaching in China generally emphasize the level of students' learning, the comprehensive evaluation criteria of their emotional attitude, students' personality and life attitude in their learning activities are not enough. The current mathematics classroom teaching evaluation standard in our country is obviously separated from the students, more is based on the experience standard of educators, lack of emotional expression of students.

\section{EVALUATION SYSTEM OF MATHEMATICS CLASSROOM TEACHING GUIDED BY CORE LITERACY}

\subsection{Evaluation Standard: Take the common development of students as the main character, promote the professional development of teachers as the leading role, promote the cultivation of students' mathematics core literacy. Realizing the scientific and systematic evaluation standard of mathematics classroom teaching.}

The basic elements of science teaching evaluation standard based on the cultivation of mathematics core quality: The evaluation is based on the course objective and course content, and embodies the basic idea of mathematics course, overall evaluation of students in knowledge and skills, mathematical thinking, problem-solving and emotional attitude and other aspects of performance. First, mathematics classroom teaching can promote the student basic knowledge and the basic skill mastery; second mathematics classroom teaching can stimulate the student's mathematics thinking and the question solution ability, the development student's mathematics thinking, promotes the student further mathematics potential; Third, through the mathematics classroom teaching, mathematics classroom teaching can develop students 'emotional attitudes and values, thus to enhance their ability of social understanding 
and participation, not only to do a good job of learning knowledge and ability, but also to become a complete person with development of students' personality. Fourth, pay attention to the development and change of students in the process of mathematics learning. Pay attention to the evaluation of students' learning process, the evaluation of students should vary from person to person.

\subsection{Evaluation Content: The Core literacy-oriented mathematics classroom teaching evaluation content includes the teacher teaching behavior and the student study state two aspects content, realizes the mathematics classroom teaching evaluation content synthesis}

Eiszner wrote in his book that "The purpose of school education is to improve the ability of students to solve problems in and out of school, and more generally, to deepen and expand the meaning that students can comprehend in their daily lives. "The same is true of classroom teaching evaluation in mathematics. The content of mathematics classroom teaching evaluation should not only be limited to the memory of knowledge which reflects the level of students' intelligence development, so that the students' acquired subject knowledge can finally return and solve the practical problems related to the subject is the focus of classroom teaching evaluation. The essence of mathematics core literacy should point to the development of students' personality and the solution of problems in real life. Therefore, the content of classroom teaching evaluation based on the cultivation of mathematics core quality should not only be based on conceptual and theoretical knowledge, but also based on situational and common sense knowledge, paying attention to the process of students' learning activities in the classroom, paying attention to students' emotional state, thinking state, participation and communication state in learning activities. Observing and evaluating students' learning state in time is helpful for students to change from passive learning to active learning and even to active learning, it is helpful for students to change from the cognitive stage of knowledge accumulation to the stage of questioning, sharing and deepening of deep problems.

\subsection{Evaluation Subject: To realize multi-subject comprehensive evaluation in mathematics classroom teaching}

Multi-subject comprehensive evaluation, as a multievaluation system based on multi-data sources, can reflect the actual teaching situation timely, comprehensively and objectively, however, the multi-subject teaching evaluation method in the specific operation of the most prone to "no focus" of the main problem, which leads to the form of this teaching evaluation, the role of low efficiency. Therefore, it is particularly important to properly deal with the problem of evaluation subject relationship. The multidimensional comprehensive evaluation takes teachers as the leading role, students as the main body, school-level competent departments as the main organizers, and teachers under the guidance of the evaluation concept of "long-term and lifelong development of students" as the fundamental goal, by judging the development potential of different students, according to the learning styles of different evaluation objects, the teaching evaluation program is tailored, the school-level supervision group carries out the school-level evaluation, and the Peer Class attendance system is implemented, by observing the classroom teaching, checking the course materials, commenting on the teaching contents and methods, and giving students the right to participate in the evaluation and the opportunity to express their demands, it fully reflects the student-centered position, the function of multi-subject comprehensive evaluation in the construction of classroom teaching evaluation mechanism is strengthened. , teachers listen to students' feedback on teaching evaluation activities, question and question the evaluation process and results, and form a good atmosphere of mutual learning to improve the quality of teaching and enhance the teaching level, at the same time, it emphasizes the students' main body consciousness and active participation ability in the mathematics classroom, through self-evaluation, peer evaluation and teacher evaluation to examine themselves and self-reflection in time, so as to promote the construction, identification and internalization of mathematics content, it lays a good foundation for the formation and development of the subject core literacy.

\subsection{Evaluation Methods: To realize the diversification of evaluation methods in mathematics classroom teaching Although the new curriculum standards suggest that teaching evaluation should be based on three-dimensional}

The subject and object of teaching evaluation take a series of means to achieve the evaluation goal and complete the evaluation task, which is called teaching evaluation way. At present, the way of evaluating mathematics classroom teaching is mainly paper-and-pencil test, which can only evaluate the students' knowledge, but it is difficult to evaluate their behavior and emotion, and it is difficult to quantify their ability. Therefore, it is necessary to introduce formative assessment. In the process of teaching, teachers pay continuous attention to students' learning behaviors, interests, attitudes and emotions through observation, conversation, communication, etc. , the evaluation will focus on the formation of students' mathematical literacy and the development of their potential, and at the same time encourage students to enhance their awareness of selfevaluation, establish a growth record bag, through the guidance of teachers, students comb themselves, sorting out the relevant achievements and works reflecting the progress of their disciplines, and their own difficulties and problems in the learning process, through the selfawareness and challenges to promote the growth of students, at the same time let the teacher see the student's 
thinking process, behavior and way of doing things. The process of the internalization of mathematics learning is long and gradual. We should pay attention to and give positive and positive evaluation to the non-intellectual factors such as the students' emotional attitude, cooperative inquiry and innovative spirit in the learning process, more conducive to the cultivation of their sense of cooperation, research spirit.

\section{CONCLUSION}

In the classroom evaluation system, based on the cultivation of mathematics core literacy, the perspective of evaluation moves from unity to diversity, and from paying attention to knowledge to comprehensive evaluation of knowledge and emotion. It no longer focuses on students' academic achievements, but more focus on students' selfawareness and self-development ability in terms of initiative and creativity in the learning process; emphasizing the diversification of evaluation subjects and methods, we can see that classroom evaluation based on the cultivation of mathematics core literacy is constantly optimized and developed under the guidance of the concept of "student-oriented".

\section{ACKNOWLEDGMENT}

This article is one of the research achievements of the 2019 Jiangxi Province University humanities and Social Science Project "research on the construction of the excellent curriculum system of the General Primary School Teachers based on the core literacy" (number: JY19143)

\section{REFERENCES}

[1] Hong Qi Chu, Concept and essence of core literacy, Journal of East China Normal University, 2016, (1): 13. (In Chinese)

[2] Chong De Lin, A study on the development of core literacy of students in the 21 st century, BEIJING:

Beijing Normal University Press. 2016. (In Chinese)

[3] ZiQi Yuan. Research on the professional accomplishment of primary school mathematics teachers based on mathematics core accomplishment, SUZHOU: Soochow University, 2016. (In Chinese)

[4] Eliot W. Eisner. Educational imagination -- school curriculum design and evaluation. Translated by Yanbing Li[M]. Beijing: Educational Science Press, 2008(In Chinese)

[5] (US) James Popham. Translated by Wang benlu and Zhao Qian. A guide to teachers' classroom teaching evaluation [M]. Chongqing: Chongqing University Press, 2010. (In Chinese)

[6] Qiquan Zhong. Curriculum evaluation: from quantitative evaluation to qualitative evaluation -- a dialogue with Japanese curriculum scholar Professor Asanuma Mao [J]. Global education outlook, 2002 (3) 